\title{
Importance of Extracellular Matrix Protein 1 (ECM1) in Maintaining the Functional Integrity of the Human Skin
}

\author{
Sandy Sercu ${ }^{1,2}$, Noritaka Oyama ${ }^{3}$ and Joseph Merregaert ${ }^{*}, 1$ \\ ${ }^{1}$ Laboratory of Molecular Biotechnology, Department of Biomedical Sciences, University of Antwerp, Belgium \\ ${ }^{2}$ Present Address: EggCentris NV, Researchpark 310, 1731 Zellik, Belgium \\ ${ }^{3}$ Dermatology and Dermato-allergology Clinic, Research Institute for Neuroscience, Southern TOHOKU General \\ Hospital, Koriyama 963-8563, Fukushima, Japan
}

\begin{abstract}
The extracellular matrix protein 1 (ECM1) is an $85 \mathrm{kDa}$ glycoprotein first identified in 1994. The threedimensional structure of ECM1 based on the third serum albumin domain was determined by in silico modelling in order to predict the most important binding site(s) of ECM1 with other protein partners in human skin. ECM1 consists of four domains: a first domain existing of $\alpha$-helices $(\alpha \mathrm{D} 1)$, the serum albumin subdomain-like (SASDL) domain 2, the sequence homology comparable with the first subdomain of the third serum albumin domain, SASDL3 and SASDL4, resulting in four "finger-like" structures ideal for binding with different proteins. A role for ECM1 was proposed in endochondral bone formation, angiogenesis and skin differentiation. Increased evidence has emerged for a pivotal biological function of ECM1 in human skin; loss of function mutations in the ECM1 gene causes the autosomal recessive genodermatosis lipoid proteinosis and auto-antibodies against ECM1 in the auto-immune disease lichen sclerosus, sharing comparable skin pathology in the affected lesions. ECM1 is capable of binding variable skin structural and extracellular matrix molecules like perlecan, laminin 332, fibulin-1C/D, fibulin-3 and heparin, as well as dermal interstitial molecules like MMP-9, collagen type IV, fibronectin, hyaluronic acid and chondroitin sulphate. In this way, ECM1 could be one of the proteins capable of connecting the basolateral surface of the epidermis through the basement membrane to the underlying dermis, which suggest a role for ECM1 as "biological glue" in maintaining skin integrity and function.
\end{abstract}

\section{INTRODUCTION}

The mouse extracellular matrix protein 1 (Ecm1) was first identified in 1994 as a novel glycosylated $85 \mathrm{kDa}$ protein secreted in the conditioned medium of the murine osteogenic stromal cell line, MN7 [1, 2]. The human ECM1 gene is located on chromosome $1 \mathrm{q} 21.2[3,4]$ and encodes for four splice variants (Fig. 1A). ECM1a (1.8kb, $540 \mathrm{aa})$ contains 10 exons and is expressed in liver, small intestines, lung, ovary, prostate, testis, skeletal muscle, pancreas, kidney, placenta, heart, basal keratinocytes, dermal blood vessels and adnexal epithelia including hair follicles and glands [3, 5-7]. ECM1b (1.4kb, 415 aa), which lacks exon 7, is detected in tonsils and the spinous and granular layers of the epidermis [5]. ECM1c (1.85kb, 559 aa) contains an extra exon 5a compared with ECM1a (Fig. 1B). Its expression was already found in the basal layer of the epidermis but its full expression pattern still has to be determined [8]. ECM1d results in a truncated protein of 57 amino acids which biological relevance is still unclear [9].

The biological function of ECM1 is not fully elucidated, but indications for its involvement in important processes like skin differentiation, endochondral bone formation and angiogenesis were found $[5,10,11]$. We have recently described the role of ECM1 in angiogenesis and its

*Address correspondence to this author at the Department of Biomedical Sciences, University of Antwerp, Laboratory of Molecular Biotechnology, Campus Drie Eiken, Universiteitsplein 1, 2610 Wilrijk, Belgium; Tel: 32-38202311; Fax: 32-3-8202239; E-mail: joseph.merregaert@ua.ac.be implications in cancer biology [12], while its putative function in the molecular pathology of lipoid proteinosis (LiP) has been reviewed by Chan $[13,33]$. In this review, we provide more insight on the role of ECM1 as a basement membrane protein, based upon recent biochemical studies, emphasizing its general importance in maintaining the structural and functional integrity of the human skin.

\section{STRUCTURE OF ECM1}

Full length human ECM1a contains a 19 amino acid signal peptide followed by four domains: (Fig. 1A) [2, 3]. The protein harbours abundant cysteine residues (4.8\%) with a typical arrangement distributed according to the $\mathrm{CC}-\left(X_{7}\right.$ 10)-C pattern of six cysteine doublets [2]. This cysteine arrangement, which is also found in serum albumin $[14,15]$ and in the sea urchin Endo16 protein [16] may form doubleloop structures $[14,17,18]$, specifying putative important biological ligand interactions [16, 19]. Recently, a rudimentary three-dimensional model was predicted using the third human serum albumin as template [20]. This model divided the ECM1a protein into four domains; an N-terminal domain of $\alpha$-helices ( $\alpha \mathrm{D} 1)$, followed by three domains comparable with a full human serum albumin subdomain: the ECM1 serum albumin subdomain-like (SASDL) 2 domain, SASDL3 and SASDL4 (Fig. 1C) [20]. Together, the serum albumin subdomain-like domains of ECM1 could form "finger-like" structures, resembling binding sites comparable with the lipid binding sites of human serum albumin, which are essential for its specific binding to different molecules. 


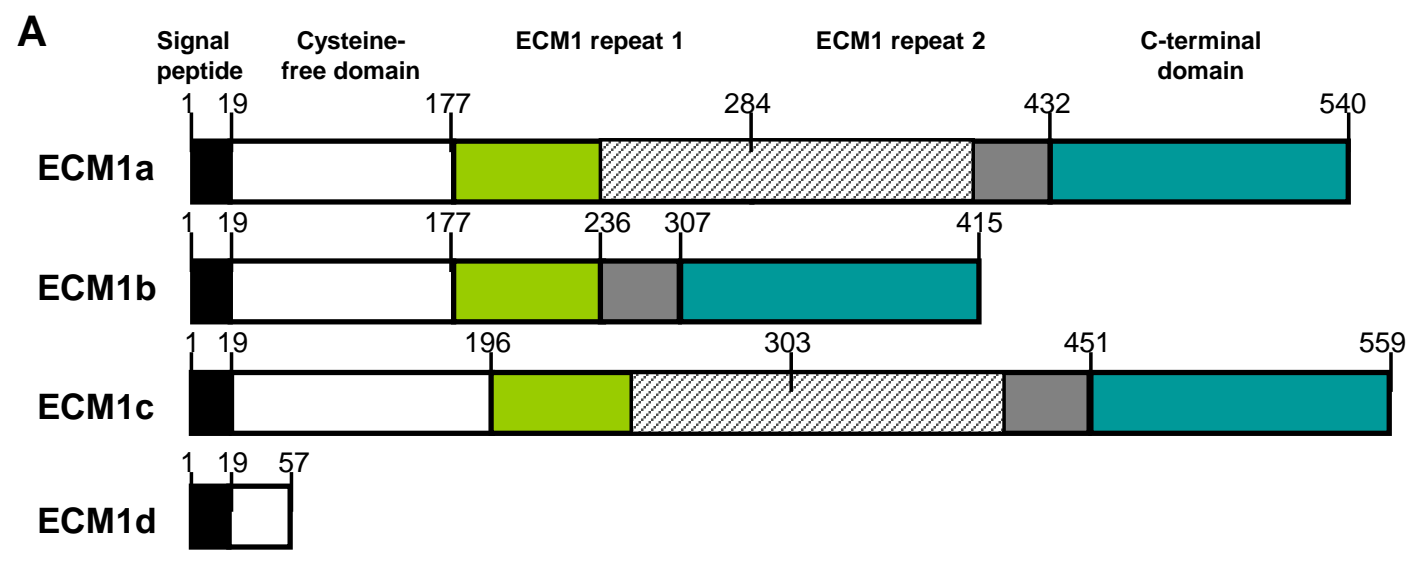

B
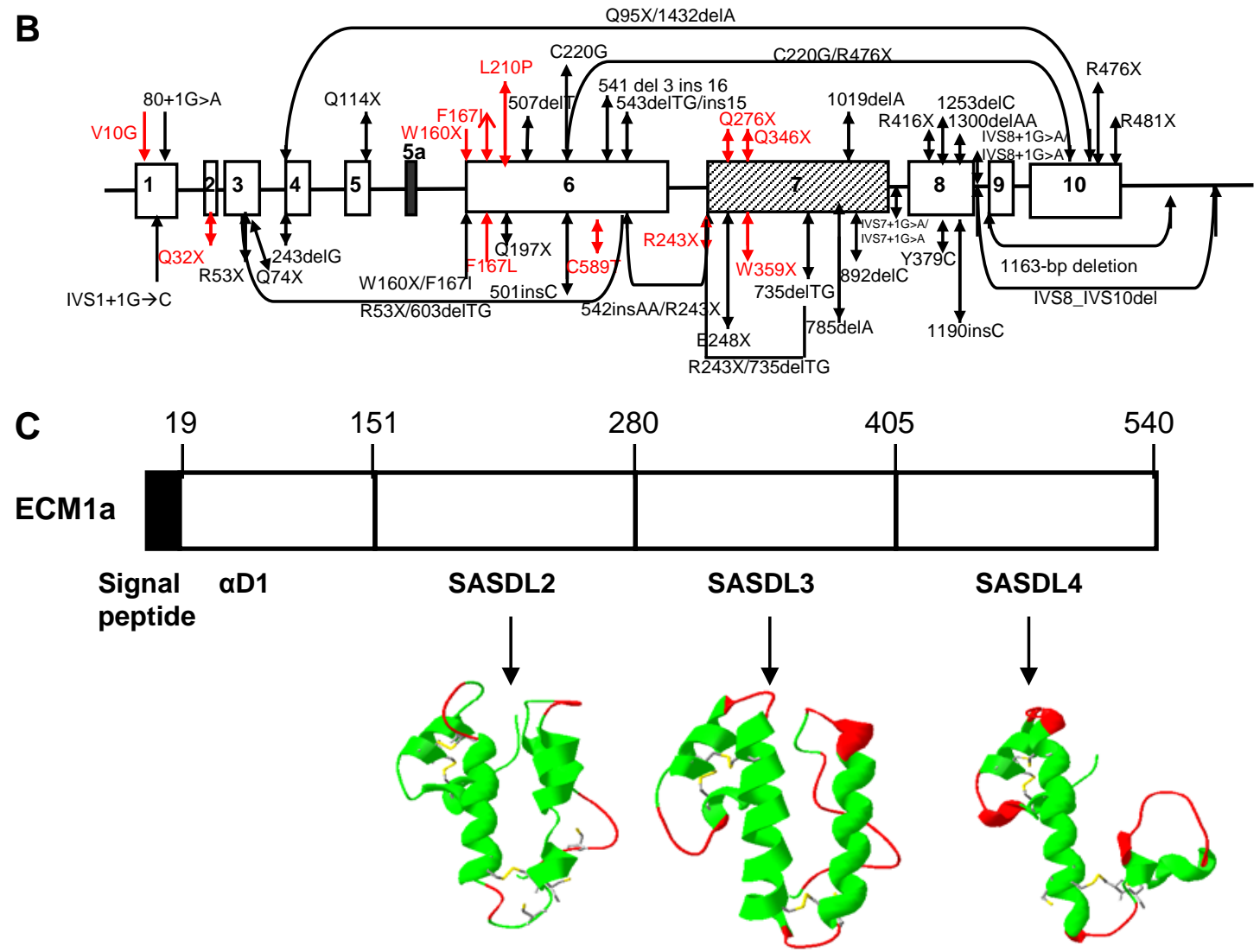

Fig. (1). Gene and domain organization of the human ECM1 gene. (A) Schematic representation of ECM1 and its four splice variants. Full-length ECM1a is divided in a signal sequence (black box) and four different domains based on the presence or absence of cysteines: an $\mathrm{N}$-terminal cysteine-free domain (white box), two tandem repeats (green and grey box), and a C-terminal region (blue box). ECM1c differs from ECM1a containing 19aa encoded by exon 5a. ECM1b results from an alternative transcript caused by splicing out exon 7 (shaded black) ECM1d encodes for a truncated protein composed of 57 amino acids containing exon 1, exon 2 and a part of exon 3 . The amino acid positions that mark the ends of each region are indicated. (B) A schematic representation of the ECM1 genomic organization. Boxes represent exons and thin lines represent introns. LiP mutations thus far reported are presented below and above the gene structure. The homozygous mutations in LiP patients are indicated with double arrows. Missense or nonsense mutations are indicated in red and frameshift mutations in black. Note that most of the mutations (nonsense and frameshift mutations) are located in exon 6 and the alternatively spliced exon 7. The positions of exon 1 (aa1-aa24), exon 2 (aa25-aa41), exon 3 (aa42-aa75), exon 4 (aa76-aa102), exon 5 (aa103-aa129), exon 6 (aa130aa236), exon 7(shaded grey: aa237-aa361), exon 8 (aa362-aa434), exon 9 (aa435-463) and exon 10 (aa464-aa540) of ECM1 in the domain structure are indicated by dotted lines. (C) A computationally predicted three-dimensional structure of ECM1a. Based on the third serum albumin domain ECM1a can be divided in four domains. The first domain containing $\alpha$-helices $(\alpha \mathrm{D} 1)$ and three serum albumin subdomainlike domains (SASDL 2-4), each three sequences comparable with a complete subdomain of the third serum albumin domain. $\alpha$ D1 exists only of $\alpha$-helices, whereas SASDL2 and 3 are capable of binding most of the extracellular matrix proteins like laminin 332, fibronectin, fibulin-1C/D, fibulin-3 or signal proteins like MMP-9. 


\section{DERMATOLOGICAL ROLE OF ECM1}

Extracellular matrix (ECM) proteins play an important role in the ECM formation, cell adhesion, cell signalling and the regulation of tissue differentiation and/or maturation [21]. Dysfunction of ECM proteins can result in a wide variety of disorders such as genodermatoses, inflammatory disorders and cancer metastasis. ECM1 is a good example of these kind of ECM proteins, because absence of ECM1 resulted in a rare genetic skin disease; lipoid proteinosis and auto-antibodies against ECM1 were found in the chronic inflammatory and scarring skin disease, lichen sclerosus [2225].

\subsection{ECM1 and its Role in Genodermatoses}

\subsubsection{ECM1 and Lipoid Proteinosis}

Mutations in ECMI are causative for LiP, an autosomal recessive disorder, also known as Urbach-Wiethe disease or hyalinosis cutis et mucosae (OMIM 247100) [26, 27]. LiP is mainly a mucocutaneous disorder characterised by laryngeal infiltration leading to hoarseness, generalised thickening and scarring of skin and mucosae, beaded eyelid papules, waxy yellow skin papules and nodules. Extracutaneous features including epilepsy, mental retardation, migraine and psychiatric abnormalities are also described [26-30]. Increased skin scaling and infiltration occur in regions exposed to mechanical friction including elbows, hands and knees [23]. Additionally, habitual sun exposed areas may show a more severely scarred and photoaged appearance when compared to the rest of the body [31].

The identification of ECMI in LiP provided the first insight into the biological significance of ECM1 in skin [23]. Up to 4 missense and 6 nonsense mutations occur in the alternatively spliced exon 7 , which leads to the ablation of the ECMIa/c transcript, but not the shorter ECMIb which lacks this exon (Fig. 1B) [22, 23, 27, 31-33]. Outside exon 7, most other mutations are found in exon 6 (missense and nonsense mutations) $[22,27,32,34-36,39]$ with the $507 \mathrm{delT}$ mutation existing as a hotspot, because of its appearance in patients with different genetic backgrounds [27, 37, 38]. From a clinical perspective, patients with mutations outside exon 7, compared to those with mutations inside exon 7, have a similar clinical presentation, but with a more severe phenotype for respiratory and skin manifestations of LiP. Extracutaneous features including epilepsy, mental retardation, migraine and psychiatric abnormalities were equally found in patients lacking only ECM1a compared with patients lacking both transcripts [26-30]. These findings favor the hypothesis that the isoforms containing exon 7 $(\mathrm{ECM} 1 \mathrm{a} / \mathrm{c})$ are of more fundamental biological importance than ECM1b [23, 27]. However, individuals sharing the same genetic background and an identical mutation in ECMI can present a different phenotype during disease progression, pointing out the heterogeneity of the disease [31].

\subsubsection{ECM1 and Lichen Sclerosus}

Lichen sclerosus is a chronic inflammatory skin disorder of unknown aetiology in which genetic, physiological and environmental factors may all contribute to susceptibility, clinical phenotype and outcome of the disease [40-42]. Patients are characterised by white indurated papules and plaques often with ecchymosis that most commonly affect the genitalia ( $85 \%$ to $98 \%$ of the cases). Symptoms can include intractable itching and soreness, and the chronic skin and mucous-membrane inflammation can lead to scarring. Some longstanding cases of genital lichen sclerosus are complicated by squamous-cell carcinoma [42].

Circulating auto-antibodies to ECM1 were found in the sera of $67 \%$ of lichen sclerosus patients $[6,24]$. There are at least three major subsets of antigenic ECM1 epitopes recognised by lichen sclerosus auto-antibodies: epitopes that are reactive for both the $\mathrm{NH}_{2}$-terminus (aa33-aa226) and $\mathrm{COOH}$-terminus (aa500-aa559); epitopes that are restricted to the $\mathrm{COOH}$-terminus alone; and epitopes restricted to a more proximal epitope (aa227-aa499). Thus, the distal second tandem repeat and the $\mathrm{COOH}$-terminal region almost cover the entire spectrum of antibody reactivity against ECM1 in lichen sclerosus sera $[24,25]$. It remains to be established whether the ECM1 auto-antibodies are of pathogenic significance or whether their presence appear to be more than just an epiphenomenon $[6,24]$. Detection of antiECM1 antibodies in lichen sclerosus may serve as a useful diagnostic marker for the disease and an indicator of clinical severity in patients. The ELISA developed and optimised by Oyama and coworkers is both highly sensitive and highly specific and provides a quick method to detect anti-ECM1 antibodies in lichen sclerosus sera [6].

\subsection{ECM1 is Not Essential for Epidermal Differentiation}

The human ECM1 gene maps to a region on chromosome $1 \mathrm{q} 21.2$ centromeric to a gene cluster generally known as the epidermal differentiation complex, showing a remarkable density of genes that fulfil important functions in epidermal differentiation [3-5, 43]. The expression of ECM1a was found in the epidermal basal layer, in dermal blood vessels, the outer root sheath of hair follicles and in sebaceous lobules and epithelium of sweat glands, while ECM1b was expressed in the suprabasal layers of the epidermis. ECM1 is also capable of binding with perlecan, an important intrinsic molecule in skin organogenesis $[8,44]$. These observations suggest a crucial role for ECM1 in epidermal differentiation $[5,7]$. However, in vitro and in vivo experiments revealed no essential role for ECM1 in the terminal differentiation process of epidermal keratinocytes [45]. Presence or absence of ECM1a/b in keratinocytes from patients with LiP did not lead to differences in epidermal differentiation. In addition, over-expression of Ecmla in vivo did not affect the stratified epidermal structure [45]. It is therefore feasible that ECM1 is dispensable for terminal differentiation of keratinocytes in unstressed conditions. However, it remains possible that in skin under stress, as a consequence of UV irradiation or traumatic injury, ECM1 will still be necessary for the maintenance of skin homeostasis. Instead of a role in splicedependent differentiation processes, differences in expression pattern of ECM1b compared with ECM1a could also implicate a more structural function for ECM1b in the region of terminally differentiated keratinocytes.

The ECM1a protein contains a typical $\mathrm{CC}-\left(\mathrm{X}_{7-10}\right)-\mathrm{C}$ arrangement, comparable with the pattern of the serum albumin family [20]. This cysteine-pattern is responsible for the generation of "double loop" domains that are involved in ligand binding. Full-length ECM1a exists of three serum albumin subdomains, while ECM1b contains only two sub- 
domains [19]. The elimination of one serum albumin subdomain in ECM1b may be responsible for exposing different binding regions, capable of binding other extracellular matrix molecules than ECM1a, necessary for the integrity of the suprabasal layers of the skin. Another indication for a putative structural role of ECM1b is the presence of two Nglycosylation sites (aa338 and aa410) modified with high mannose type oligosaccharides [46]. The evidence that extracellular glycoproteins are actually modified with high mannose type oligosaccharides indicates that epidermal cells project high mannose glycans to the cell surface and may be involved in molecular recognition events, which could indicate a role for ECM1 in signal transduction pathways. ECM1b was found to be upregulated by a diffusible factor secreted by stromal cells. The induction and upregulation of $E C M 1 b$ RNA expression is dependent on the capacity of the cells to terminally differentiate [5].

\subsection{ECM1 Plays an Important Role in the Maintenance of the Dermal-Epidermal Communication}

After cloning of the ECM1 gene in 1997 [3], its expression in human tissues and its role in human diseases such as LiP and lichen sclerosus has been demonstrated [5, 23, 24]. However, the underlying mechanisms through which the ECM1 mutations lead to a warty epidermal thickening, scarring and dermal hyalinosis are not well understood. Recently, it has been shown that ECM1a/c expression, in addition to its expression in the epidermal basal layer, was also found in the network-like suprastructures of the skin basement membrane, containing laminin 332 and collagen type IV [47]. The skin basement membrane at the dermalepidermal junction has an important function in tightly linking the epidermis to the underlying dermis, and providing a barrier to epidermal migration. Once the basement membrane has been assembled, stratification of the epidermis proceeds, with the proliferating cells attached to the basement membrane and the daughters cells migrating into the upper layers [48, 49]. The importance of ECM1 in linking the dermal-epidermal junction has been emphasised by its ability to bind important extracellular molecules of the basement membrane zone like perlecan [8], fibulin-1C-and D [50], matrix metalloproteinase (MMP)-9 [51], laminin 332 $[20,47]$ fibulin-3 [20], collagen type IV, heparin, hyaluronic acid and chondroitin sulphate A [47] (Fig. 2). Not only is ECM1 a capable of binding laminin 332 and collagen IV but it also enhances the binding between laminin 332 and collagen IV themselves [47]. Taken together, ECM1 may act as "biological glue" to maintain the integrity of the skin. However, the molecular mechanism underlying interactions of these molecules has to be studied in more detail. The "biological glue" theory has been supported by the different binding regions that were found in ECM1 interacting with various extracellular matrix molecules in skin. The $\mathrm{NH}_{2}$ terminal part of ECM1a is capable of binding with type IV collagen [47] in contrast to the second tandem repeat of ECM1a which binds MMP-9 [52], laminin 332 [20, 47] and fibulin-1C and D [50]. Perlecan interacts with the C-terminal part of ECM1a [8], while fibulin-3 bind to one of the two tandem repeats of ECM1a [20]. The importance of the different binding regions was further illustrated by the presence of auto-antibodies in the sera from lichen sclerosus patients, whose circulating IgGs are reactive with $\mathrm{NH}_{2}$ - and $\mathrm{COOH}-$
ECM1. These antibodies may attack the interaction of ECM1 with its interacting partners, which could be the cause of further intense damage to ECM1-matrix assembly in skin. The discovery of the important binding regions of ECM1 might be a starting point of understanding the heterogeneous reactivity of antibodies with ECM1 in lichen sclerosus sera. Furthermore, the role of ECM1 in dermal-epidermal expression has been demonstrated by organotypic keratinocyte monocultures treated with diffusible growth factors, like epidermal growth factor (EGF) and granulocyte-monocytecolony stimulating factor (GM-CSF) secreted by stromal cells (our unpublished data). Upregulation of ECM1 in the epidermis after addition of these growth factors indicates dermal/epidermal interaction through fibroblasts which seems to be essential for the synthesis and deposition of this molecule. Interaction can be based upon 1) production of soluble factors by either epithelial (after being activated by e.g. growth factors) or mesenchymal cells that exhibit autocrine and/or paracrine activities [52];2) cell-matrix interactions [53] or 3) signalling by direct cell-cell contact [54]. Through the release of interleukin (IL)-1, keratinocytes can enhance release of growth factors such as GM-CSF [55], IL-6 or IL-8 [56] in dermal cells, which in turn stimulate basement membrane formation. EGF is a strong stimulus for MMP-9 production [57] which plays an important role in keratinocyte migration and granulation tissue remodeling [58]. It is possible that EGF stimulates the induction of MMP-9 which is capable of interacting with ECM1. This interaction could be necessary for a normal wound healing. Absence of ECM1, like in LiP patients, leads to the ablation of this binding explaining the granulation tissue in regions exposed to mechanical friction [27].

\section{ECM1 EXPRESSION IS ALTERED IN SKIN AGE- ING}

Ageing of the skin is a natural process that has fascinated researchers for decades, since the basic principles underlying intrinsic skin ageing are thought to have general relevance for common degenerative connective tissue diseases like osteoarthritis, osteoporosis and arteriosclerosis [59]. Superimposed on this intrinsic process, extrinsic ageing is related to UV-induced damage of the dermis (photoageing) [60]. Cellular changes as well as qualitative and quantitative alterations of dermal extracellular matrix proteins are involved, resulting in dyspigmentation, loss of recoil capacity and tensile strength with wrinkle formation, increased fragility, impaired wound healing and malignancies [61, 62]. Alterations in collagen, the major structural component of the skin, have been considered to be a cause of skin ageing and are observed in naturally aged and photoaged skin [63].

ECM1 was proposed to play a role in skin adhesion, differentiation, scarring, angiogenesis and basement membrane integrity, which are all important processes in the intrinsic (chronological) as well as the extrinsic (photo) ageing process [13].

\subsection{ECM1 Expression is Decreased in Chronological Ageing}

Intrinsic ageing is influenced by several factors, including genetics, hormonal changes and metabolic processes. It affects the skin by a slow and partly reversible degeneration of connective tissue, which results in a de- 


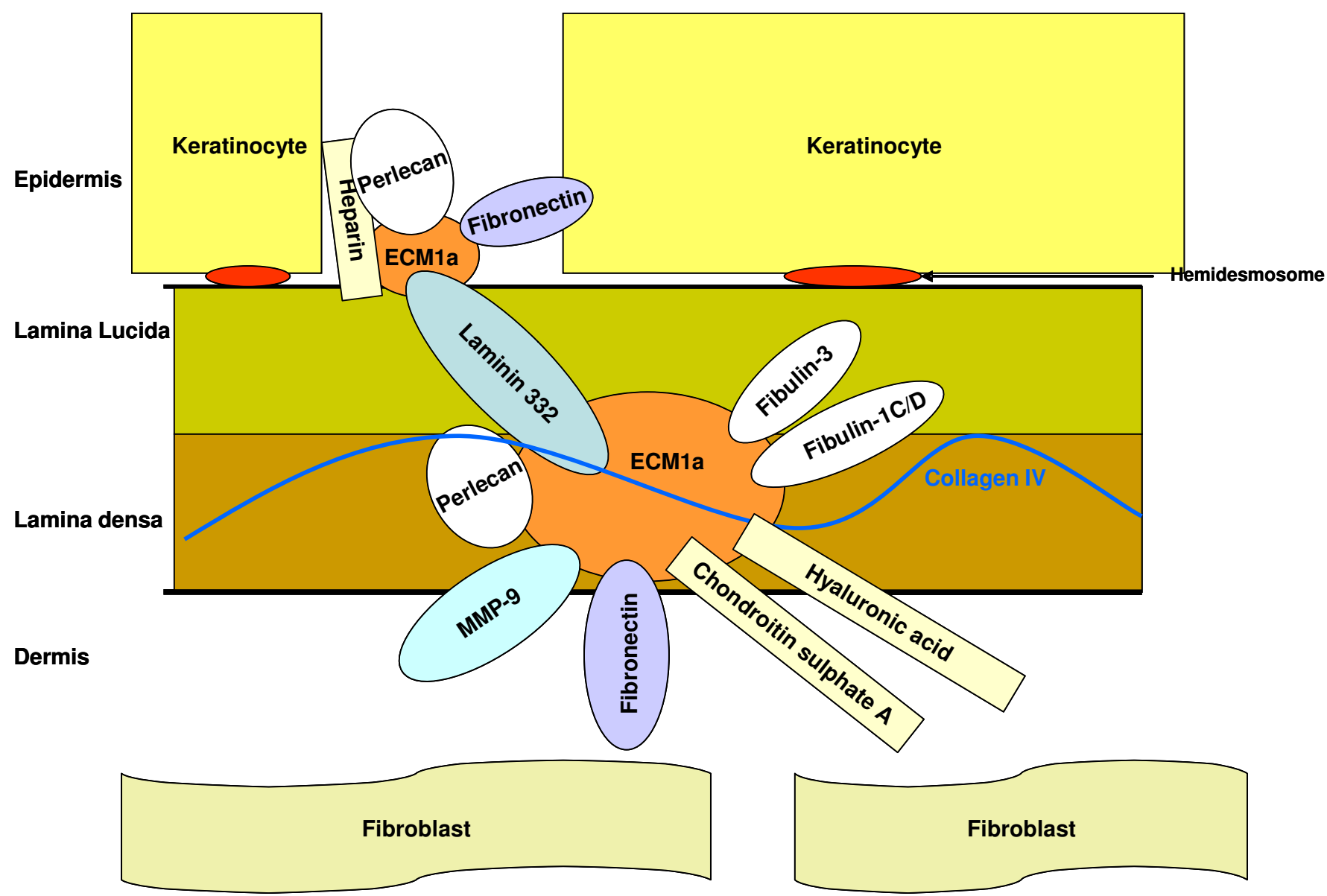

Fig. (2). Summary of the different binding partners of ECM1 in the dermal-epidermal junction. The basal keratinocytes in human skin is finely anchored to the underlying superficial dermal components, forming hemidesmosomes. Some of these anchoring proteins are secreted by keratinocytes as well as fibroblasts like the heparin binding perlecan or fibronectin. Other proteins are specific for the lamina lucida like laminin 332, fibulin-1 and 3 or the lamina densa like collagen type IV of the basement membranes. Typical dermal proteins are MMP-9, chondroitin sulphate A and hyaluronic acid. We have omitted the remaining proteins which are thought to be currently uninvolved in ECM1 interaction(s), ie. bullous pemphigoid antigen I and II, and integrins.

creased epidermal and dermal thickness by $10-50 \%$ between the age of 30 and 80 years [64]. Structural components of the extracellular matrix such as interstitial collagen and elastin are reduced and the content of cross-links in collagen fibers is increased, which increases stiffness of the skin. Aged skin is also typified by an enhanced release of matrix-degrading metalloproteases $[62,63,65]$, which results in a decreased level of ECM and reduced elastin and fibrillin-1 expression.

ECM1 is one of these downregulated ECM proteins in intrinsically aged skin protected from chronic UV exposure [7]. The decreased ECM1 expression in chronologically aged skin may have profound effects on dermal and epidermal homeostasis, leading to the clinical features of atrophy in both of the layers, including the loss of adnexal epithelia. However, the pathway(s) mediated by ECM1 remains unclear. The mouse Ecm 1 promotor contains a functional binding site for the transcription factor AP1 (composed of the Jun and Fos protein family) well known for its role in skin ageing. However, the c-Fos protein expression in young and aged skin is unaltered, while c-Jun is increased in aged skin [66]. ECM1 is capable of binding with MMP-9 [51], which has a proteolytic effect on type IV collagen. Downregulation of ECM1 could result in free MMP-9 which is capable of cleaving type IV collagen into tumstatin. Tumstatin activates transforming growth factor (TGF)- $\beta$ which is a multifunctional cytokine that plays an important role in the synthesis of extracellular connective tissue. TGF- $\beta$ is known to stimulate the proliferation of fibroblasts and to induce the synthesis and secretion of ECM proteins, such as collagen, tropo-elastin, and fibrillin-1 [66-68]. In addition, TGF- $\beta$ downregulates the expression of proteolytic enzymes, such as MMP-3 and MMP-9, which degrade ECM [69, 70].

\subsection{ECM1 Expression is Involved in Photoageing}

Photoageing of the skin is a complex biologic process affecting various layers of the skin with the major damage seen in the dermal connective tissues [62]. Well-known acute clinical affects of UV irradiation in the skin are inflammation (sunburn) and reactive epidermal hyperplasia and thickening of the stratum corneum, while repeated sun exposure leads to a dysregulation of melanocyte density [71]. The photo-damaged dermis is characterised by replacement of the normal fibrillary pattern by large quantities of abnormal, thickened, degraded and non-functional elastic fibers, which resembles elastin, although it finally degenerate into a nonfibrous, homogeneous and amorphous mass [72]. This amor- 
phous mass can be generated through transformation of both pre-existing normal collagen and elastic network as well as abnormal synthetic activities of the fibroblasts via cytokine release from epidermal keratinocytes [71]. Degradation and remodelling of collagen was found in photodamaged skin leading to a histological decrease in collagen fibers and bundles [72]. Collagen degradation is compensated by either the elastotic material that is compact and uniform or by a mixture of water and ground substance like proteoglycans and glycosaminoglycans which are accumulated and deposited abnormally within the elastotic material $[73,74]$. Collagen is the main component of the dermis constituting $75 \%$ of the dry weight. More than $70 \%$ exists of type I collagen and $15 \%$ of type III collagen [75]. The collagen type III concentration in the dermis increases after UV-irradiation [76].

LiP patients from sunny regions have a more severe phenotype compared to patients in less sunny countries. In one LiP patient one observed that areas which were habitually exposed to the sun showed more scarring and photoaged appearance compared with non-exposed areas [31]. These findings suggest a photoprotective role of ECM1 in human skin. Recently, a higher expression of ECM1 was found in both lower and upper layers of the human epidermis, induced by chronically UV-exposure, when compared to UVprotected skin [7]. UV-irradiation stimulates fibroblasts to produce matrix degradating matrix metallo proteinases like MMP-1, MMP-3 and MMP-9; increases the presence of mixed inflammatory cell infiltrates and decreases the number of irregularly dilated blood vessels [72]. MMP-3 degrades important ECM proteins like collagen IV, laminin 332, fibronectin and proteoglycans (perlecan) which are all binding partners of ECM1 [77]. Further study is necessary to define the exact role of ECM1 in this UV irradiation process. UV exposure activates JNK and p38 which results in activation of the transcription factor AP1, which in turn activates MMP-1, MMP-3 and MMP-9 [78, 79]. The human ECM1 regulatory region contains a conserved AP1 binding site which has been proven to be functional in mice [80]. It is possible that upregulation of AP1 is responsible for the increasing concentration of ECM1 in skin after UVirradiation.

\section{CONCLUSIONS}

ECM1 is an extracellular matrix protein present in the dermal-epidermal junction. Structural analysis of ECM1 revealed typical domains for protein-protein interaction compared to those of serum albumin (Fig. 1B), which are capable of binding with structural and extracellular matrix molecules of the skin like perlecan [8], laminin 332 [20, 47], fibulin-1C/D [51], fibulin-3 [20] and heparin [47], as well as dermal interstitial molecules like MMP-9 [52], collagen type IV, fibronectin, hyaluronic acid and chondroitin sulphate [47]. It seems that ECM1 contributes in connecting the basolateral surface of the epidermis through the basement membrane to the underlying dermis (Fig. 2). ECM1 utilizes different binding regions to interact with various molecules. Binding of these extracellular matrix molecules could be very important in different processes, since auto-antibodies against ECM1 present in the sera of lichen sclerosus patients are capable of attacking every binding site used by the interaction partners of ECM1 [6, 24]
Histological analysis of LiP patients revealed large deposits of laminin 332, type IV collagen, nidogen and perlecan [81]. ECM1 is capable to interact with laminin 332 and collagen type IV and its binding even enhances the binding between laminin 332 and collagen IV themselves [47]. These findings indicate a role for ECM1 in the basement membrane stabilisation. Disruption of this gene will cause absence of the ECM1 protein which may lead to an unstable laminin $332 /$ collagen IV binding and accumulation of unbound perlecan. Destabilisation of this binding may cause an accumulation of both proteins, explaining the depositions of these proteins in the dermis. However, a mouse model for LiP will be necessary for better understanding of the LiP pathophysiology and the importance of the ECM1-extracellular matrix components interactions in vivo.

In addition to its structural role, ECM1 could be a regulatory factor, which plays a role in skin organogenesis, because of its possible binding with heparin [47]. It is known that heparin-binding growth factors like perlecan are involved in organogenesis [44]. In vitro and in vivo experiments have shown that ECM1 is not essential for normal epidermal differentiation [45]. It is possible that other epidermal proteins will mask the real function of ECM1, so it would be very interesting to check what effect the absence of ECM1 in skin under stress (trauma or UV-irradiation) has on the epidermal differentiation.

Major questions are now, at which stages and how ECM1 is involved in basement membrane formation and its maintenance? And what kind of signal transduction pathways are capable of regulating the ECM1 protein in different important processes like UV-mediated apoptosis and epidermal differentiation.

\section{ACKNOWLEDGEMENTS}

This work was supported by a grant from the "Fund for Scientific Research-Flandres" (FWO-G.0133.05) to J. Merregaert. S. Sercu was recipient of a fellowship from the ' Instituut voor Wetenschappelijk en Technologisch Onderzoek' (IWT, Belgium).

\section{REFERENCES}

[1] Mathieu E, Meheus L, Raymackers J, Merregaert J. Characterization of the osteogenic stromal cell line MN7: identification of secreted MN7 proteins using two-dimensional polyacrylamide gel electrophoresis, western blotting, and microsequencing. J Bone Miner Res 1994; 9: 903-13.

[2] Bhalerao J, Tylzanowski P, Filie JD, Kozak CA, Merregaert J. Molecular cloning, characterization, and genetic mapping of the cDNA coding for a novel secretory protein of mouse. Demonstration of alternative splicing in skin and cartilage. J Biol Chem 1995; 270: 16385-94.

[3] Smits P, Ni J, Feng P, et al. The human extracellular matrix gene 1 (ECM1): genomic structure, cDNA cloning, expression pattern, and chromosomal localization. Genomics 1997; 45: 487-95.

[4] Johnson MR, Wilkin DJ, Vos HL, et al. Characterization of the human extracellular matrix protein 1 gene on chromosome $1 \mathrm{q} 21$. Matrix Biol 1997; 16: 289-92.

[5] Smits P, Poumay Y, Karperien M, et al. Differentiation-dependent alternative splicing and expression of the extracellular matrix protein 1 gene in human keratinocytes. J Invest Dermatol 2000; 114 : 718-24.

[6] Oyama N, Chan I, Neill SM, et al. Development of antigen-specific ELISA for circulating autoantibodies to extracellular matrix protein 1 in lichen sclerosus. J Clin Invest 2004; 113: 1550-59.

[7] Sander CS, Sercu S, Ziemer M, et al. Expression of extracellular matrix protein 1 (ECM1) in human skin is decreased by age and in- 
creased upon ultraviolet exposure. Br J Dermatol 2006; 154: 21824.

[8] Mongiat M, Fu J, Oldershaw R, Greenhalgh R, Gown AM, Iozzo RV. Perlecan protein core interacts with extracellular matrix protein 1 (ECM1), a glycoprotein involved in bone formation and angiogenesis. J Biol Chem 2003; 278: 17491-9.

[9] Horev L, Potikha T, Ayalon S, et al. A novel splice-site mutation in ECM-1 gene in a consanguineous family with lipoid proteinosis. Exp Dermatol 2005; 14: 891-7.

[10] Deckers M, Smits P, Karperien M, et al. Recombinant human extracellular matrix protein 1 inhibits alkaline phosphatase activity and mineralization of mouse embryonic metatarsals in vitro. Bone 2001; 28: 14-20.

[11] Han Z, Ni J, Smits P, et al. Extracellular matrix protein 1 (ECM1) has angiogenic properties and is expressed by breast tumor cells. FASEB J 2001; 15: 988-94.

[12] Sercu S, Zhang L, Merregaert J. The extracellular matrix protein 1: its molecular interaction and implication in tumor progression. Cancer Invest 2008; 26: 375-84.

[13] Chan I. The role of extracellular matrix protein 1 in human skin. Clin Exp Dermatol 2004; 29: 52-6.

[14] Brown JR. Structural origins of mammalian albumin. Fed Proc 1976; 35: 2141-4.

[15] Yang F, Brune JL, Naylor SL, Cupples RL, Naberhaus KH, Bowman $\mathrm{BH}$. Human group-specific component $(\mathrm{Gc})$ is a member of the albumin family. Proc Natl Acad Sci USA 1985; 82: 7994-8.

[16] Godin RE, Urry LA, Ernst SG. Alternative splicing of the Endo16 transcript produces differentially expressed mRNAs during sea urchin gastrulation. Dev Biol 1996; 179: 148-59.

[17] Carter DC, He XM, Munson SH, et al. Three-dimensional structure of human serum albumin. Science 1989; 244: 1195-201.

[18] Vogelaar NJ, Lindberg U, Schutt CE. Crystallization and preliminary X-ray analysis of $\mathrm{Gc}$, the vitamin D-binding protein in serum. J Mol Biol 1991; 220: 545-7.

[19] Kragh-Hansen U. Structure and ligand binding properties of human serum albumin. Dan Med Bull 1990; 37: 57-84.

[20] Sercu S, Lambeir AM, Steenackers E, et al. ECM1 interacts with fibuline- 3 and the beta 3 chain of laminin 332 through its serum albumin subdomain-like 2 domain. Matrix Biol 2009; in press.

[21] Davis C, Fischer J, Ley K, Sarembock IJ. The role of inflammation in vascular injury and repair. J Thromb Haemost 2003; 1: 16991709.

[22] Hamada T. Lipoid proteinosis. Clin Exp Dermatol 2002; 27: 624-9.

[23] Hamada T, McLean WH, Ramsay M, et al. Lipoid proteinosis maps to $1 \mathrm{q} 21$ and is caused by mutations in the extracellular matrix protein 1 gene (ECM1). Hum Mol Genet 2002; 11: 833-40.

[24] Oyama N, Chan I, Neill SM, et al. Autoantibodies to extracellular matrix protein 1 in lichen sclerosus. Lancet 2003; 362: 118-23.

[25] Chan I, Oyama N, Neill SM, Wojnarowska F, Black MM, McGrath JA. Characterization of IgG autoantibodies to extracellular matrix protein 1 in lichen sclerosus. Clin Exp Dermatol 2004; 29: 499504.

[26] Urbach EWC. Lipoidosis cutis et mucosae. Virchows Arch Path Anat $1929 ; 273: 285-319$.

[27] Hamada T, Wessagowit V, South AP, et al. Extracellular matrix protein 1 gene (ECM1) mutations in lipoid proteinosis and genotype-phenotype correlation. J Invest Dermatol 2003; 120: 345-50.

[28] Siebert M, Markowitsch HJ, Bartel P. Amygdala, affect and cognition: evidence from 10 patients with Urbach-Wiethe disease. Brain 2003; 126: 2627-37.

[29] Teive HA, Pereira ER, Zavala JA, et al. Generalized dystonia and striatal calcifications with lipoid proteinosis. Neurology 2004; 63: 2168-9.

[30] Claeys KG, Claes LR, Van Goethem JW, et al. Epilepsy and migraine in a patient with Urbach-Wiethe disease. Seizure 2007; 16: $465-8$

[31] Van Hougenhouck-Tulleken W, Chan I, Hamada T, et al. Clinical and molecular characterization of lipoid proteinosis in Namaqualand, South Africa. Br J Dermatol 2004; 151: 413-23.

[32] Di Giandomenico S, Masi R, Cassandrini D, El-Hachem M, Bruno C, Santorelli FM. Lipoid proteinosis: case report and review of the literature. Acta Otorhinolaryngol Ital 2006; 26: 162-7.

[33] Chan I, Liu L, Hamada T, Sethuraman G, McGrath J. The molecular basis of lipoid proteinosis: mutations in extracellular matrix protein 1. Exp Dermatol 2007; 16: 881-90.
[34] Lupo I, Cefalu AB, Bongiorno MR, et al. A novel mutation of the extracellular matrix protein 1 gene (ECM1) in a patient with lipoid proteinosis (Urbach-Wiethe disease) from Sicily. Br J Dermatol 2005; 153: 1019-22.

[35] Wang CY, Zhang PZ, Zhang FR, Liu J, Tian HQ, Yu L. New compound heterozygous mutations in a Chinese family with lipoid proteinosis. Br J Dermatol 2006; 155: 470-2.

[36] Han B, Zhang X, Liu Q, Chen X, Zhu X. Homozygous missense mutation in the ECM1 gene in Chinese siblings with lipoid proteinosis. Acta Derm Venereol 2007; 87: 387-9.

[37] Chan I, Bingewar G, Patil K, Nayak C, Wadhwa SL, McGrath JA. An Indian child with lipoid proteinosis resulting from a recurrent frameshift mutation (507delT) in the extracellular matrix protein 1 gene. Br J Dermatol 2004; 151: 726-7.

[38] Uchida T, Hayashi H, Inaoki M, Miyamoto T, Fujimoto W. A failure of mucocutaneous lymphangiogenesis may underlie the clinical features of lipoid proteinosis. Br J Dermatol 2007; 156: 152-7.

[39] Chan I, Sethuraman G, Sharma VK, Bruning E, Hamada T, McGrath JA. Molecular basis of lipoid proteinosis in two Indian siblings. J Dermatol 2004; 31: 764-6.

[40] Meffert JJ, Davis BM, Grimwood RE. Lichen sclerosus. J Am Acad Dermatol 1995; 32: 393-416.

[41] Powell JJ, Wojnarowska F. Lichen sclerosus. Lancet 1999; 353: 1777-83.

[42] Tasker GL, Wojnarowska F. Lichen sclerosus. Clin Exp Dermatol 2003; 28: 128-33.

[43] Mischke D, Korge BP, Marenholz I, Volz A, Ziegler A. Genes encoding structural proteins of epidermal cornification and S100 calcium-binding proteins form a gene complex ("epidermal differentiation complex") on human chromosome 1q21. J Invest Dermatol 1996; 106: 989-92.

[44] Sher I, Zisman-Rozen S, Eliahu L, et al. Targeting perlecan in human keratinocytes reveals novel roles for perlecan in epidermal formation. J Biol Chem 2006; 281: 5178-87.

[45] Sercu S, Poumay Y, Herphelin F, et al. Functional redundancy of extracellular matrix protein 1 in epidermal differentiation. $\mathrm{Br} \mathrm{J}$ Dermatol 2007; 157: 771-5.

[46] Uematsu R, Furukawa J, Nakagawa H, et al. High throughput quantitative glycomics and glycoform-focused proteomics of murine dermis and epidermis. Mol Cell Proteomics 2005; 4: 1977-89.

[47] Sercu S, Zhang M, Oyama N, et al. Interaction of extracellular matrix protein 1 with extracellular matrix components: ECM1 is a basement membrane protein of the skin. J Invest Dermatol 2008; 128: 1397-409.

[48] Bohnert A, Hornung J, Mackenzie IC, Fusenig NE. Epithelialmesenchymal interactions control basement membrane production and differentiation in cultured and transplanted mouse keratinocytes. Cell Tissue Res 1986; 244: 413-29.

[49] Barrandon Y, Green H. Cell migration is essential for sustained growth of keratinocyte colonies: the roles of transforming growth factor-alpha and epidermal growth factor. Cell 1987; 50: 1131-7.

[50] Fujimoto N, Terlizzi J, Aho S, et al. Extracellular matrix protein 1 inhibits the activity of matrix metalloproteinase 9 through highaffinity protein/protein interactions. Exp Dermatol 2006; 15: 300-7.

[51] Fujimoto N, Terlizzi J, Brittingham R, Fertala A, McGrath JA, Uitto J. Extracellular matrix protein 1 interacts with the domain III of fibulin-1C and 1D variants through its central tandem repeat 2 . Biochem Biophys Res Commun 2005; 333: 1327-33.

[52] Smola H, Thiekotter G, Fusenig NE. Mutual induction of growth factor gene expression by epidermal-dermal cell interaction. J Cell Biol 1993; 122: 417-29.

[53] Gailit J, Clark RA. Wound repair in the context of extracellular matrix. Curr Opin Cell Biol 1994; 6: 717-25.

[54] Waelti ER, Inaebnit SP, Rast HP, et al. Co-culture of human keratinocytes on post-mitotic human dermal fibroblast feeder cells: production of large amounts of interleukin 6. J Invest Dermatol 1992; 98: 805-8.

[55] Werner S, Smola H. Paracrine regulation of keratinocyte proliferation and differentiation. Trends Cell Biol 2001; 11: 143-6.

[56] Boxman IL, Ruwhof C, Boerman OC, Lowik CW, Ponec M. Role of fibroblasts in the regulation of proinflammatory interleukin IL-1, IL-6 and IL-8 levels induced by keratinocyte-derived IL-1. Arch Dermatol Res 1996; 288: 391-8.

[57] Lyons JG, Birkedal-Hansen B, Pierson MC, Whitelock JM, Birkedal-Hansen H. Interleukin-1 beta and transforming growth factor- 
alpha/epidermal growth factor induce expression of M(r) 95,000 type IV collagenase/gelatinase and interstitial fibroblast-type collagenase by rat mucosal keratinocytes. J Biol Chem 1993; 268: 19143-51.

[58] McCawley LJ, O'Brien P, Hudson LG. Epidermal growth factor (EGF)- and scatter factor/hepatocyte growth factor (SF/HGF)- mediated keratinocyte migration is coincident with induction of matrix metalloproteinase (MMP)-9. J Cell Physiol 1998; 176: 255-65.

[59] Krieg T, Hein R, Hatamochi A, Aumailley M. Molecular and clinical aspects of connective tissue. Eur J Clin Invest 1988; 18: 105-23.

[60] Fisher GJ, Kang S, Varani J, et al. Mechanisms of photoaging and chronological skin aging. Arch Dermatol 2002; 138: 1462-70.

[61] Leyden JJ. Clinical features of ageing skin. Br J Dermatol 1990; 122(Suppl 35): 1-3.

[62] Wlaschek M, Tantcheva-Poor I, Naderi L, et al. Solar UV irradiation and dermal photoaging. J Photochem Photobiol 2001; 63: 4151 .

[63] Varani J, Warner RL, Gharaee-Kermani M, et al. Vitamin A antagonizes decreased cell growth and elevated collagen-degrading matrix metalloproteinases and stimulates collagen accumulation in naturally aged human skin. J Invest Dermatol 2000; 114: 480-6.

[64] Lock-Andersen J, Therkildsen P, de Fine OF, et al. Epidermal thickness, skin pigmentation and constitutive photosensitivity. Photodermatol Photoimmunol Photomed 1997; 13: 153-8.

[65] Chung JH, Seo JY, Choi, HR, et al. Modulation of skin collagen metabolism in aged and photoaged human skin in vivo. J Invest Dermatol 2001; 117: 1218-24

[66] Massague J. TGF-beta signal transduction. Annu Rev Biochem 1998; 67: 753-91.

[67] Pupe A, Moison R, van Henegouwen GB, et al. Eicosapentaenoic acid, a n-3 polyunsaturated fatty acid differentially modulates TNFalpha, IL-1alpha, IL-6 and PGE2 expression in UVB-irradiated human keratinocytes. J Invest Dermatol 2002; 118: 692-8.

[68] Son JK, Son MJ, Lee E, et al. Ginkgetin, a Biflavone from Ginko biloba leaves, inhibits cyclooxygenases-2 and 5-lipoxygenase in mouse bone marrow-derived mast cells. Biol Pharm Bull 2005; 28: 2181-4.

[69] Eickelberg O, Kohler E, Reichenberger F, et al. Extracellular matrix deposition by primary human lung fibroblasts in response to TGF-beta1 and TGF-beta3. Am J Physiol 1999; 276: L814-L824.
[70] Hall MC, Young DA, Waters JG, et al. The comparative role of activator protein 1 and Smad factors in the regulation of Timp-1 and MMP-1 gene expression by transforming growth factor-beta 1 . J Biol Chem 2003; 278: 10304-13.

[71] Wulf HC, Sandby-Moller J, Kobayasi T, Gniadecki R. Skin aging and natural photoprotection. Micron 2004; 35: 185-91.

[72] Kligman LH, Kligman AM. The nature of photoaging: its prevention and repair. Photodermatology 1986; 3: 215-27.

[73] de Rigal J, Escoffier C, Querleux B, Faivre B, Agache P, Leveque JL. Assessment of aging of the human skin by in vivo ultrasonic imaging. J Invest Dermatol 1989; 93: 621-5.

[74] Bernstein EF, Chen YQ, Kopp JB, et al. Long-term sun exposure alters the collagen of the papillary dermis. Comparison of sunprotected and photoaged skin by northern analysis, immunohistochemical staining, and confocal laser scanning microscopy. J Am Acad Dermatol 1996; 34: 209-18.

[75] Lovell CR, Smolenski KA, Duance VC, Light ND, Young S, Dyson M. Type I and III collagen content and fibre distribution in normal human skin during ageing. Br J Dermatol 1987; 117: 419 28.

[76] Plastow SR, Lovell CR, Young AR. UVB-induced collagen changes in the skin of the hairless albino mouse. J Invest Dermatol 1987; 88: 145-8.

[77] Kim HH, Cho S, Lee S, et al. Photoprotective and anti-skin-aging effects of eicosapentaenoic acid in human skin in vivo. J Lipid Res 2006; 47: 921-30.

[78] Fisher GJ, Talwar HS, Lin J, et al. Retinoic acid inhibits induction of c-Jun protein by ultraviolet radiation that occurs subsequent to activation of mitogen-activated protein kinase pathways in human skin in vivo. J Clin Invest 1998; 101: 1432-40.

[79] Assefa Z, Garmyn M, Vantieghem, et al. Ultraviolet B radiationinduced apoptosis in human keratinocytes: cytosolic activation of procaspase-8 and the role of Bcl-2. FEBS Lett 2003; 540: 125-32.

[80] Smits P, Bhalerao J, Merregaert J. Molecular cloning and characterization of the mouse Ecml gene and its 5' regulatory sequences. Gene 1999; 226: 253-61.

[81] Mirancea N, Hausser I, Beck R, Metze D, Fusenig NE, Breitkreutz D. Vascular anomalies in lipoid proteinosis (hyalinosis cutis et mucosae): basement membrane components and ultrastructure. J Dermatol Sci 2006; 42: 231-9

(C) Sercu et al.; Licensee Bentham Open.

This is an open access article licensed under the terms of the Creative Commons Attribution Non-Commercial License (http://creativecommons.org/licenses/by$\mathrm{nc} / 3.0 /$ ) which permits unrestricted, non-commercial use, distribution and reproduction in any medium, provided the work is properly cited. 